\title{
Pelatihan Mikrotik Dalam Rangka Persiapan Ujian Kompetensi Keahlian (UKK) SMK Negeri 1 Kuala Kampar
}

\author{
Abdul Syukur ${ }^{1 *}$, Akmar Efendi ${ }^{1}$, Apri Siswanto ${ }^{1}$, Yudhi Arta ${ }^{1}$ \\ 1Program Studi Teknik Informatika, Fakultas Teknik, Universitas Islam Riau, Jalan Kaharuddin \\ Nasution 113, Pekanbaru, Riau, Indonesia - 28284 \\ *Penulis koresponden: abdulsyukur@eng.uir.ac.id
}

\begin{tabular}{l} 
Info Artikel \\
\hline Riwayat : \\
Dikirim 16 Maret 2020 \\
Diterima 30 April 2020 \\
Dipublikasi 12 Mei 2020 \\
\hline
\end{tabular}

\section{Kata Kunci :}

Mikrotik

Kompetensi

Komputer

Pendidikan

Teknologi

\begin{abstract}
Abstrak
Di era digital seperti saaat ini lulusan Sekolah Menengah Pertama cenderung lebih memilih Sekolah Menengah Kejuruan (SMK) daripada Sekolah Menengah Umum (SMU) atau Madrasah Aliyah (MA) untuk melanjutkan pendidikannya. SMK menjadi lebih populer karena banyak faktor. Salah satu faktor tersebut adalah lulusan SMK dianggap lebih siap menghadapi dunia kerja. Salah satu SMK di Riau adalah SMK Negeri 1 Kuala Kampar. Sekolah yang berstatus kepemilikan pemerintah daerah ini berdiri pada tahun 2015 dengan tanggal SK pendirian 20 Desember 2015. Teknik Komputer Jaringan (TKJ) menjadi salah satu jurusan yang diandalkan di sekolah ini karena jurusan ini memiliki peserta didik lebih banyak daripada jurusan lainnya. Akan tetapi sangat disayangkan jumlah gu ru produktif jurusan TKJ di sekolah ini sangat minim. Hal itu terjadi karena banyak guru PNS yang SK pengangkatannya ditempatkan di sekolah ini meminta mutasi kepada Dinas Pendidikan Provinsi Riau ke daerah perkotaan. Letak sekolah yang agak terisolasi dan jauh dari kota menjadi salah satu alasan mereka enggan mengajar di sekolah tersebut dan kemudian melakukan mutasi. Setiap tahunnya Ujian Kompetensi Keahlian (UKK) jurusan TKJ terdiri atas tiga paket dan ketiga paket tersebut menggunakan router mikrotik untuk dikerjakan oleh siswa secara praktek
\end{abstract}

\section{PENDAHULUAN}

Di era digital seperti saaat ini lulusan Sekolah Menengah Pertama cenderung lebih memilih Sekolah Menengah Kejuruan (SMK) daripada Sekolah Menengah Umum (SMU) atau Madrasah Aliyah (MA) untuk melanjutkan pendidikannya. SMK menjadi lebih populer karena banya $\mathrm{k}$ faktor. Salah satu faktor tersebut adalah lulusan SMK dianggap lebih siap menghadapi dunia kerja (Utami \& Dwityanto, 2016). Adanya Praktik Kerja Lapangan (PKL) atau Praktik Kerja Industri (Prakerin), komposisi praktik yang lebih banyak daripada teori, dan penjurusan yang dimulai sejak awal pendidikan membuat lulusan SMK lebih terampil dibandingkan dengan lulusan sekolah menengah atas lainnya.

Salah satu SMK di Riau adalah SMK Negeri 1 Kuala Kampar. SMK ini berada di Kecamatan Kuala Kampar Kabupaten Pelalawan Provinsi Riau tepatnya di Jalan Lintas Pantai Bono Tanjung Umbut, Sungai Emas. Sekolah yang berstatus kepemilikan pemerintah daerah ini berdiri pada tahun 2015 dengan tanggal SK pendirian 20 Desember 2015. SMK Negeri 1 Kuala Kampar Kecamatan Kuala Kampar Kabupaten Pelalawan terdiri atas tiga penjurusan 
yaitu Pertanian dan Teknik. Tiga penjurusan tersebut dibagi lagi menjadi delapan kompetensi keahlian, yakni Agribisnis Tanaman, Agribisnis Tanaman Pangan dan Holtikultura, Agribisnis Tanaman Perkebunan, Teknik Komputer dan Jaringan, dan Teknik Sepeda Motor.

Teknik Komputer Jaringan (TKJ) menjadi salah satu jurusan yang diandalkan di sekolah ini karena jurusan ini memiliki peserta didik lebih banyak daripada jurusan lainnya. Akan tetapi sangat disayangkan jumlah guru produktif jurusan TKJ di sekolah ini sangat minim. Hal itu terjadi karena banyak guru PNS yang SK pengangkatannya ditempatkan di sekolah ini meminta mutasi kepada Dinas Pendidikan Provinsi Riau ke daerah perkotaan. Letak sekolah yang agak terisolasi dan jauh dari kota menjadi salah satu alas an mereka enggan mengajar di sekolah tersebut dan kemudian melakukan mutasi.

Proses belajar mengajar di sekolah ini pun kurang efektif. Hampir setiap hari peserta didik tidak bisa belajar produktif sesuai dengan kurikulum Direktorat Pembinaan SMK. Sumber daya manusia yakni tenaga pengajar (guru) tidak mumpuni dalam mentransfer ilmunya karena bukan berasal dari tamatan bidang informatika. Seharusnya seorang guru harus mengajar sesuai bidang keahliannya agar ilmu yang sampai ke siswa dapat diserap dengan maksimal sesusai dengan kurikulum yang telah disusun. Selain itu kondisi sekolah belum memiliki aliran listrik dari PLN. Listrik sekolah masih menggunakan mesin diesel yang merupakan fasilitas sekolah. Apabila mesin diesel ini mengalami kerusakan atau kehabisan bahan bakar maka peserta didik tidak bisa belajar praktikum menggunakan komputer.

Selain daripada itu tujuan workshop/pelatihan mikrotik adalah agar siswa bisa mempersiapkan diri menghadapi Ujian Kompetensi Keahlian (UKK) dan persiapan mengikuti "Olimpiade Jaringan MikroTik Indonesia". Menurut Asosiasi Penyelenggara Jasa Internet Indonesia (APJII) dalam https://olimpiade.mikrotik.id bahwa penyelenggaraan acara "Olimpiade Jaringan MikroTik Indonesia" bertujuan mengasah dan mendorong penguasaan ilmu jaringan untuk siswa Sekolah Menengah Kejuruan (SMK) di Indonesia, khususnya SMK yang memiliki jurusan Teknis Komputer dan Jaringan (TKJ). Kemampuan mengelola jaringan ini adalah salah satu keterampilan yang dibutuhkan oleh dunia kerja, seiring dengan hampir semua jenis perusahaan bermigrasi menggunakan sistem komputerisasi dan jaringan. Dijelaskan juga bahwa MikroTik adalah salah satu perangkat jaringan yang saat ini banyak digunakan di dunia industri dan operator telekomunikasi. Keterampilan untuk membuat konfigurasi MikroTik juga banyak diajarkan di SMK-SMK (Purwanto, 2015), khususnya yang memiliki jurusan TKJ. Bahkan lebih dari 200 SMK telah terdaftar sebagai MikroTik Academy, program kerja sama dengan MikroTik yang memberikan hak bagi SMK untuk menyelenggarakan pelatihan dan ujian sertifikasi MikroTik Certified Network Associates (MTCNA).

\section{METODE PELAKSANAAN}

Berdasarkan uraian terkait solusi permasalahan mitra diatas, kami tim PKM Universitas Islam Riau akan merinci metode pelaksanaan selama kegiatan PKM ini berlangsung.

1. Workshop jaringan mikrotik yang akan dilaksanakan secara intensif.

Pelatihan langsung menggunakan alat berupa router mikrotik sehingga peserta didik akan lebih mudah memahami materi karena mengerjakannya secara nyata. Materi pada workshop ini menggunakan kurikulum dari mikrotik sehingga materinya sudah diakui secara internasional.

2. Adapun tempat dan waktu pelaksanaan kegiatan workshop PKM ini akan dilaksanakan di laboratorium komputer SMK Negeri 1 Kuala Kampar Kabupaten Pelalawan selama dua hari untuk kelas XII TKJ. 
3. Workshop jaringan mikrotik akan disampaikan langsung oleh ketua tim PKM Univeritas Islam Riau yang akan didampingi oleh anggota dosen dan anggota mahasiswa.

4. Anggota dosen selama workshop akan membantu secara teknis untuk membantu peserta didik dalam melakukan konfigurasi router/pemasangan kabel-kabel yang digunakan atau melakukan troubleshooting jika terjadi kendala teknis kepada peserta didik.

5. Anggota mahasiswa dalam hal ini akan membantu ketua tim PKM dalam segala hal administrasi seperti pembuatan laporan singkat dan dokumentasi dalam bentuk foto atau video selama kegiatan workshop PKM.

6. Dalam pelaksanaan workshop jaringan mikrotik ini akan dilaksanakan dengan dua metode. Pertama penyampaian konsep materi tentang jaringan, termasuk penjelasan fitur-fitur dan fungsi router mikrotik. Kedua, penerapan langsung konsep materi yang telah disampaikan atau praktikum.

\section{HASIL DAN PEMBAHASAN}

Kegiatan pengabdian pada masyarakat yang dilaksanakan dengan penyampaian materi, tatap muka dan tanya jawab berjalan dengan baik dan lancar. Pertemuan tatap muka dengan metode ceramah dan konfigurasi (demonstrasi), dilanjutkan tanya jawab ini sangat antusias diikuti oleh peserta kegiatan yang berada di SMK Negeri 1 Kuala Kampar.

Hasil kegiatan pengabdian kepada masyarakat secara garis besar mencakup beberapa komponen sebagai berikut:

1. Keberhasilan target jumlah peserta workshop

2. Ketercapaian tujuan workshop

3. Ketercapaian target materi yang telah direncanakan

Pelaksanaan kegiatan pengabdian kepada masyarakat ini dilakukan oleh 4 orang dosen dan 1 orang mahasiswa Program Studi Teknik Informatika, Fakultas Teknik, Universitas Islam Riau. Pokok pembahasan yang disampaikan terdiri:

1. Jaringan Komputer

2. Konsep Topologi Jaringan

3. MikroTik

Kegiatan yang diawali dengan ceramah dan demonstrasi ini kemudian dilanjutkan tanya jawab. Program pengabdian kepada masyarakat berupa membangun router menggunakan Mikrotik RouterOS (Mollick, Biswas, Halder, \& Salmani, 2016), di sekolah ini diharapkan dapat menambah informasi, pengetahuan, dan lebih percaya diri siswa -siswi dalam kehidupan sehari-harinya. Hasil workshop ini akan bermanfaat bagi masyarakat, dalam peningkatan informasi tentang pembelajaran di sekolah. Disamping itu dengan adanya workshop ini akan menambah keterampilan siswa-siswa SMK untuk meningkatkan kompetensi diri mereka sehingga membantu dalam peningkatan kemampuan dan kemudahan dalam mencari pekerjaan.

\section{KESIMPULAN}

Program kegiatan pengambdian kepada masayarakat ini dapat diselenggarakan dengan baik dan berjalan dengan lancar sesuai dengan rencana kegiatan yang telah disusun meskipun belum semua peserta dari siswa dan siswi menguasai dengan baik materi yang disampaikan. Kegiatan ini mendapat sambutan sangat baik terbukti dengan keaktifan peserta mengikuti pendampingan dengan tidak meninggalkan tempat sebelum waktu workshop berakhir 


\section{UCAPAN TERIMA KASIH}

Terima kasih kepada Lembaga Penelitian dan Pengabdian Kepada Masyarakat (LPPM) Universitas Islam Riau yang telah memberikan dukungan dana terselenggaranya kegiatan ini melalu kontrak no. 587/PkM/KONTRAK/LPPM-UIR/10-2018

\section{DAFTAR PUSTAKA}

Mollick, P., Biswas, S., Halder, A., \& Salmani, M. (2016). Mikrotik Router Configuration using IPv6. International Journal of Innovative Research in Computer, 4(2), 2001-2007.

Purwanto, E. (2015). Implementasi Jaringan Hotspot Dengan Menggunakan Router Mikrotik Sebagai Penunjang Pembelajaran (Studi Kasus: Smk Sultan Agung Tirtomoyo Wonogiri). Jurnal Informa, 1(2), 20-27.

Utami, A. S., Dwityanto, A., \& Psi, S. (2016). Hubungan antara dukungan sosial dengan kesiapan kerja siswa SMK. Universitas Muhammadiyah Surakarta. 